\title{
NETWORK TIES' GOVERNANCE IN ENTREPRENEURIAL NETWORKING OF SMES: CASES OF THE OWNER- MANAGERS IN THE SOUTHERN REGION OF MALAYSIA
}

\author{
Siti Sarah Omar ${ }^{*}$, Malcolm Higgs², Chan Shiau Wei', and Muazam Ali ${ }^{1}$ \\ ${ }^{1}$ Faculty of Technology Management and Business, \\ Universiti Tun Hussein Onn Malaysia, 86400 Batu Pahat, Johor, Malaysia \\ ${ }^{2}$ Southampton Business School, University of Southampton, Highfield, \\ Southampton SO17 1BJ, United Kingdom \\ *Corresponding author: sarah@uthm.edu.my
}

Published online: 30 June 2020

To cite this article: Omar, S.S., Higgs, M., Chan, S.W., \& Ali, M. (2020). Network ties' governance in entrepreneurial networking of SMEs: Cases of the owner-managers in the southern region of Malaysia. Asian Academy of Management Journal, 25(1), 85-101. https://doi.org/10.21315/aamj2020.25.1.5

To link to this article: https://doi.org/10.21315/aamj2020.25.1.5

\begin{abstract}
There were inconsistent findings on the network ties' governance on the strength of relationship thus supporting the need to empirically prove the variations associated with the elements of entrepreneurial networking. This study aims to explore how the ownermanagers decide the network governance of network ties strength in their relationships in entrepreneurial networking. Specifically, the objective of the study is to determine the governance of network tie strength in entrepreneurial networking. This is a qualitative study involving eight cases of small-sized food manufacturing firms in the southern region of Malaysia using an in-depth interview technique with the owner-managers. The triangulation of data has been carried out by interviewing individuals who are seen as strong and weak ties of the network. This study found that the strength of ties was not only based on the strong intimacy and high emotional attachment (SIHEA) and trust, but also governed by the tie's human capital (knowledge, skills, experiences, networking); their attitudes and values that dominate the contents of network relationships. It also found that these themes are integrated among each other in entrepreneurial networking. This study adds value to both network and human capital literature. Only few research studies have examined the network ties among small and medium-sized enterprises (SMEs) in Malaysia.
\end{abstract}

Keywords: network tie, human capital, trustworthiness, SMEs, entrepreneurial networking

(C) Asian Academy of Management and Penerbit Universiti Sains Malaysia, 2020. This work is licensed under the terms of the Creative Commons Attribution (CC BY) (http://creativecommons. org/licenses/by/4.0/). 


\section{INTRODUCTION}

The small and medium-sized enterprises (SMEs) face the lack of financing problem in the early stage of their start-up business. Social network provides an opportunity to gain the required financial and human resources from the competitive market (Teixeira et al., 2019). It supports in the capital formation and resources utilisation. Both personal and business networks are necessary in acquiring various financial resources, tangible, intangible, family support, informational, human and professional networking which support the implementation of business plan into the practical form (Brieger \& De Clercq, 2019; Meyskens et al., 2010). Resource mobilisation also requires the networking facility. Efficient and effective network further accelerate the SMEs business performance and profit.

The significance of the social network for the sustainable development of entrepreneurship business has been recognised by the emerging research scholars (Bansal et al., 2019; Greco \& De Jong, 2017). However, there are various aspect of social networks, like strong ties and weak ties which are the heart of social network and important variable of discussion (Durda \& Ključnikov, 2019; Soetanto, 2017; Lux et al., 2016). Efficient social networking increases the chances of entrepreneurial success while providing new opportunities, gaining human and financial capital, and acquiring the acknowledgement from other firms (Agbim, 2019; Klyver et al., 2018; Lux et al., 2016). Social network has many advantages: it gives access to knowledge, skill, information, human and financial capital, and other resources. Schell et al. (2018) argued that a well-organised and professional social network with regard to the quantity and quality of ties is very important for the starting of new entrepreneurial business.

Nonetheless, the methods and procedures by which specific network ties make a valuable addition in the emerging business still need to be clear. Gaps are found in the existing theories, in understanding and explaining the various role and importance of these social entrepreneurial networks (Tran \& Von Korflesch, 2016; Lechner \& Dowling, 2003). These inconsistences need to be understood with the support of relevant literature and empirical studies. In this study we will explore how the owner-managers decide the network governance of network ties strength in their relationships in entrepreneurial networking. It is a qualitative study involving eight cases of small-sized food manufacturing firms in the southern region of Malaysia using an in-depth interview technique with the owner-managers. 


\section{LITERATURE REVIEW}

This section provides a discussion on the strong and weak network ties, the theories associated with these, and the arguments on the mix of these ties.

\section{Strong versus Weak Ties}

Ties with family members, relatives, and close friends are regarded as strong (Granovetter, 1983). This is due to the fact that relations with these parties have long existed and exchanges have already taken place within these relationships. It is argued that strong ties are more supportive and more easily available to provide assistance to entrepreneurs (Granovetter, 1973). Furthermore, they tend to connect similar people in long-term and intense relationships (Elfring \& Hulsink, 2007), thus promoting the development of trust and the transfer of fine-grained information and tacit knowledge to entrepreneurs (Rowley et al., 2000).

Weak ties, on the other hand, refer to the wider set of relations with whom an entrepreneur has infrequent or occasional and intermittent contact (Elfring \& Hulsink, 2007; Granovetter, 1973). These free and unemotional relationships tend to increase the chances of meeting new business contacts (Opondo, 2017). In addition, weak ties such as customers, suppliers or new business friends serve as channels for entrepreneurs to access a wide variety of resources: information such as new business locations, potential market for goods and services, discussion and advice, sources of capital (Paerregaard, 2018), and supplier and customer referrals (Jack et al., 2004). Further, Granovetter (1973) suggests that weak ties provide information that is not readily available by strong ties and this he regards as the "strength of weak tie." Brashears and Quintane (2018) state that, even though weak ties are regarded as providing redundant information, they, however, may certainly not result in non-redundant contacts. Voluminous network literature (for example, Aldrich \& Zimmer, 1986; Birley et al., 1991; Dubini \& Aldrich, 1991), however, emphasised the importance of weak ties on the relative value of strong versus weak ties (Soetanto, 2017).

Granovetter (1973) and Burt (1992) argue that a perfect entrepreneurial network must contain a combination of strong and weak ties because the nature of these ties has impacts on the operation and structure of networks. Findings from many entrepreneurial and network studies supported this argument, such as the works of Shu et al. (2018), Soetanto (2017), and Ren et al. (2016). These authors found that the accurate blends of strong and weak ties are essential to ensure the effectiveness of an entrepreneur's social network. Chell and Baines (2000) found that not only weak ties but also strong ties contributed to business growth. These different ties 
are necessary for different reasons and functions (Lechner \& Dowling, 2003). For example, weak ties are used for certain purposes such as recruitment while strong ties promote mutual trust (Chell \& Baines, 2000; Rowley et al., 2000). Rowley et al.'s (2000) study of the steel and semiconductor industry found that the combinations of strong and weak ties are positively related to firm performance depending on the conditions surrounding the firms.

Besides that, while many empirical studies supported the argument on the need of the mix of strong and weak ties in entrepreneurial venture, Rost (2011) and Jack (2005) found otherwise. The findings show that strong ties are more effective than weak ties in new venture development. Bruderl et al. (1992) carried out a study of 1,700 new business ventures in Germany; their most striking result indicated that the spouse or life partner and family support seem to be crucial resources for an entrepreneur and had a positive impact on business survival. Conversely, weak ties were found to be a poor predictor of firm performance. Subsequently, Jack's (2005) ethnographic study of 14 respondents found that strong ties are vital for entrepreneurial activities as they aid knowledge and information acquisition, and also uphold and enrich business and personal reputations. Jack, however, shows that strong ties provide both opportunities and constraints to the new venture. This offers some evidence in support of Granovetter's idealism that strong ties as well as weak ties are equally important in the entrepreneurial venture.

\section{Network Ties' Governance}

Network governance refers to the mechanisms that coordinate network exchange (Hoang \& Antoncic, 2003). Trust is the most important mechanism for network exchange that provides a good quality for the resource flows (Larson, 1992; Lorenzo \& Lipparini, 1999). Trust influences the intensity and richness of exchange relations particularly in relation to the exchange of information (Hirsch et al., 2018; Huang \& Knight, 2017; Ren et al., 2016). Hoang and Antoncic (2003) noted other network mechanisms such as power and influence and the "threat of ostracism and loss of reputation" (p.170). How network exchange happens is also very closely related to the strengths of the relationships between the entrepreneurs and their network ties. Previous research highlighted the variations between the bases for strong ties and the weak ties; and the roles of strong ties and weak ties have been discussed extensively (Omar et al., 2009).

In revealing the theme trustworthiness, there are two strands to this theme. Firstly, the discussions of trust around the network exchange transaction between the entrepreneur and the weak ties, and secondly trust development as the intensity of the relationship increased. This discussion is also developed on two subthemes 
of trust - affective and cognitive. Affective trust is related to emotional and social relations resulting in sincere concern for a network tie's welfare and a belief in the relationship's essential quality (Smith \& Lohrke, 2008). In contrast, cognitive trust happens when a person makes a decision to trust based on knowledge or capabilities; that he/she acknowledges, understands and predicts from routine interactions with the network ties (Akrout \& Diallo, 2017).

According to Brush et al. (2001), gaining desired human and financial capital for the formation of new enterprise is a big issue which entrepreneurs have to face. Social networking plays an important role in the starting of new business activities, its supports in capital formation and make position in the competitive environment of market (Teixeira et al., 2019). People utilise their personal and professional networks in the process of business formation and achieved various resources financial, tangible, intangible, family support, informational, human, and professional networking which support the implementation of business plan in to the practical form (Brieger \& De Clercq, 2019; Meyskens et al., 2010). Mobilisation of self-contacts requires the social development activities (Granovetter, 1973) and individual networking performance matter in the resource gathering (Dubini \& Aldrich, 2002). Effective social networks accelerate the process of new business creation. It influences new business development and contributes in the exploration of innovative opportunities (Jiang et al., 2018).

Research scholars Brown and Duguid (2017) argued that the idea of social networking makes our concentration on the entrepreneurship a holistic thing rather than an individual issue. Likewise, Ozdemir et al. (2016) observed network as a method of knowing the embeddedness of entrepreneurship performance, where "embeddedness" means that all the social, economic, and other business performance and actions are influenced by the actor's dyadic relations and by the structure of the whole social network relations. Jones and Conway (2004, p. 91) sight the network perspective as promising a "conceptualization of the entrepreneurial process as a complex and pluralistic pattern of interactions, exchanges, and relationships between actors." In summary, this study is governed by three main bases of network governance that are strong intimacy and high emotional attachment (SIHEA) (Granovetter, 1983), trust (Larson, 1992; Lorenzo \& Lipparini, 1999; Jack, 2005; Smith \& Lohrke, 2008) and reciprocal commitment (Granovetter, 1983; Soderquist \& Chetty, 2009). 


\section{METHODOLOGY}

This study is an interpretive qualitative study involving eight cases to illuminate the details of network ties' governance of SMEs in Malaysia by using in-depth interview technique. The interview sessions lasted between 40 minutes and two hours with each of the SME business owners. Interviews were also conducted with the strong or weak ties to fulfil the purpose of data triangulation. Besides, researcher has also constituted her reflexivity in the study by taking into account the understanding and awareness of her position as a researcher when dealing with the respondents, the data, and also the audience (readers). Data were transcribed and analysed manually using thematic analysis.

\section{ANALYSIS AND DISCUSSION}

\section{The Governance of Network Ties' Strength}

This section provides a cross-case analysis and discusses these variations of governance of network ties' strengths. This study found that these three elements (strong intimacy and high emotional attachment, trust, and reciprocal commitment) are the basis for the network ties of the eight cases and discovered two new emerging themes (human capital and attitude/values). In addition, a notable finding from this study is that, for a network tie to become a strong tie relationship to the entrepreneur, one element has to be integrated with another.

Table 1 shows the summary of the bases for the strong tie relationship in each case, with diverse network actors. It can be summarised that most cases regard their strong ties as the family members who are formally and informally involved in the business, governed by a strong intimacy and high emotional attachment. The table also shows that strong relationships with other actors in the business environment such as customers and suppliers are based on trustworthiness and reciprocal commitment. New emerging findings show that ties' human capital and attitude are significant for entrepreneurs when deciding the strengths of their relationships. These themes are explored in subsequent detail. 


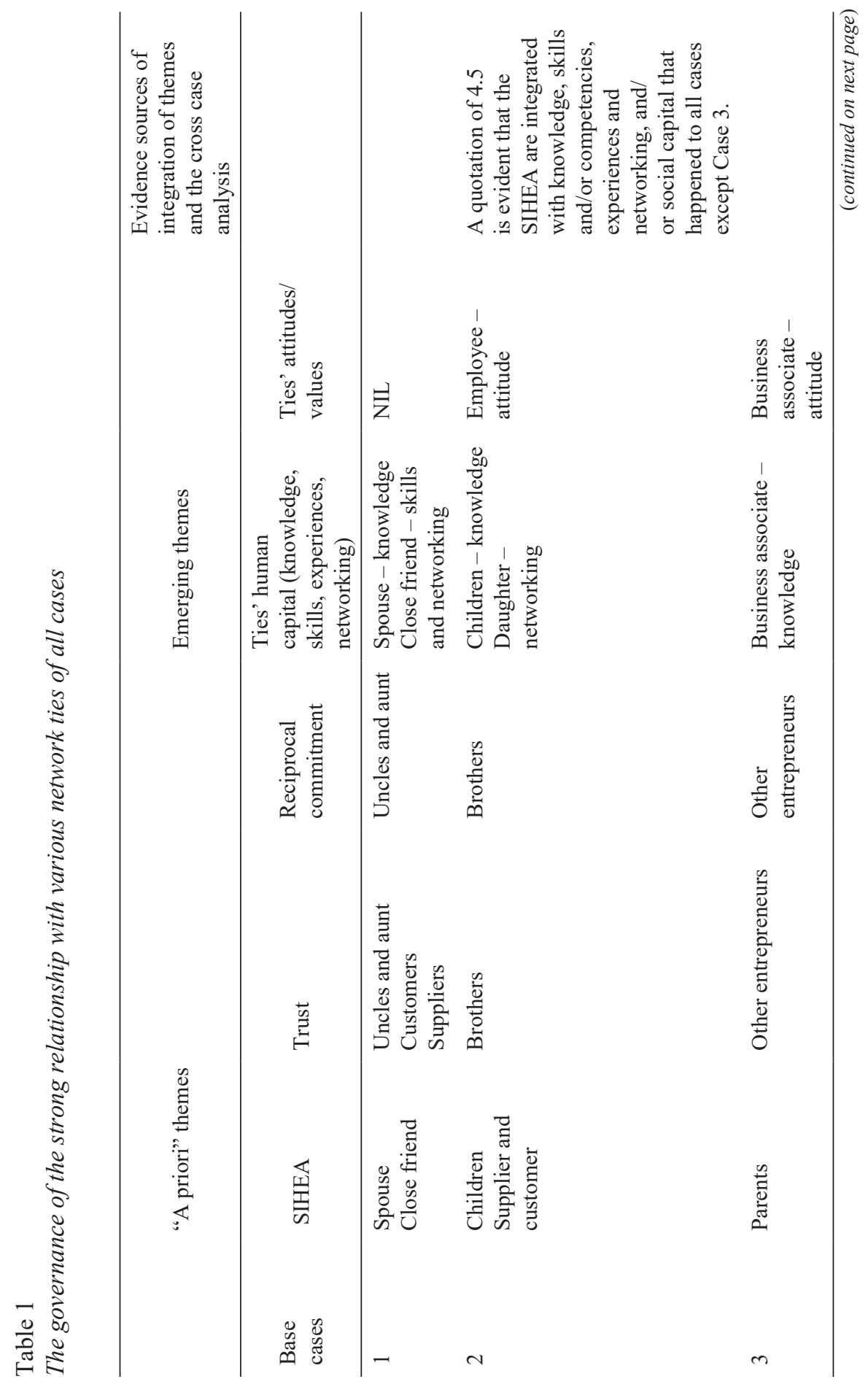


Siti Sarah Omar et al.

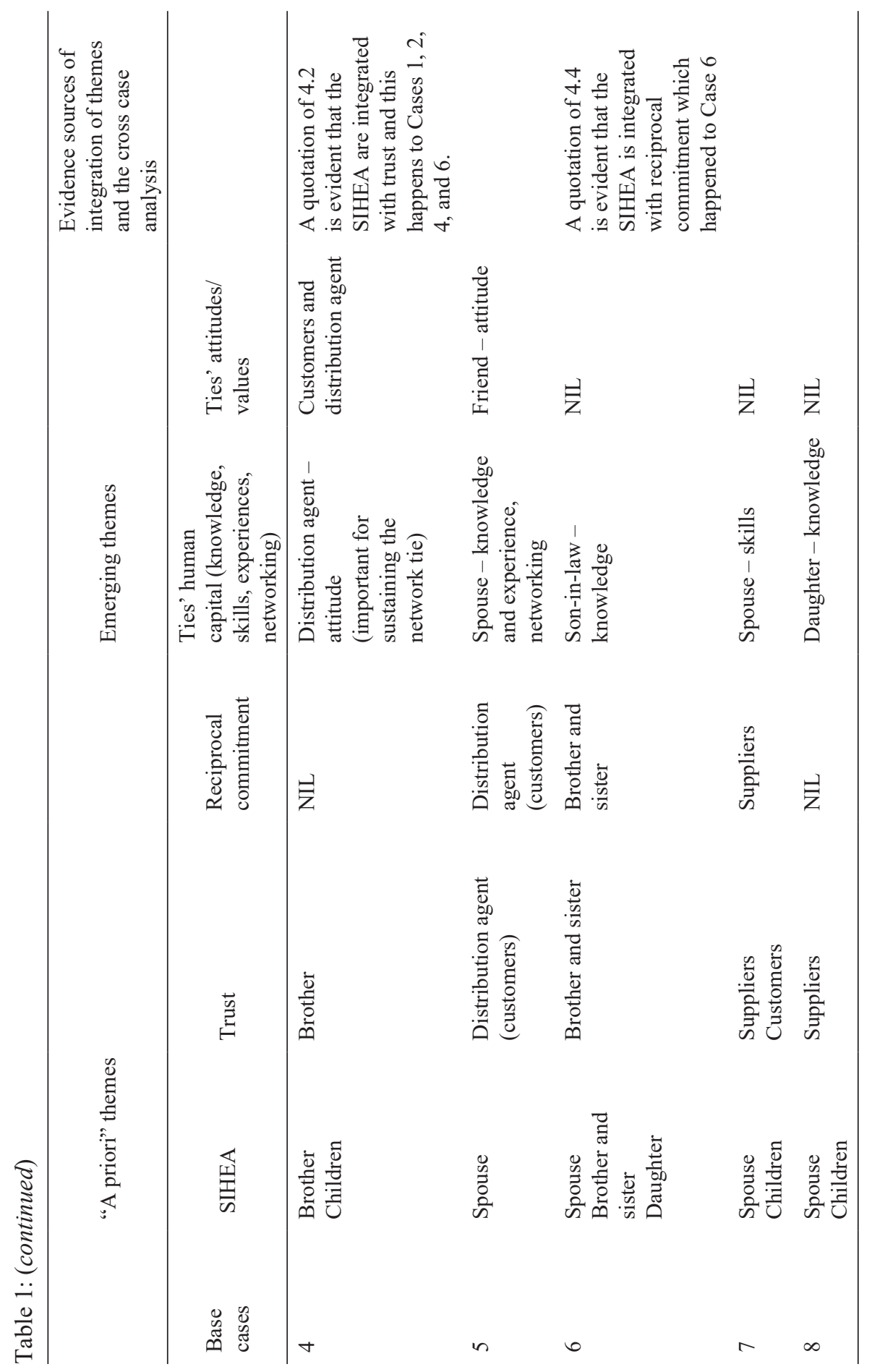




\section{SIHEA}

The SIHEA was identified as the foundation for the strong tie relationships of the entrepreneurs with family, their spouses and close friends. This finding is in line with the proposition by Granovetter (1983) and previous studies by Dahl and Sorenson (2009). SIHEA is claimed as instrumental in a strong network tie relationship, and it is presided over by mutual love and affection. Dahl and Sorenson (2009) found that entrepreneurs in Denmark chose being closer to family and friends than other factors that influence the performance of the business in deciding where to locate their businesses.

The family ties in the context of this study can be distinguished into two different types of kin - the immediate kin and the extended kin. The immediate kin are parents, children (adult), and siblings (brothers and sisters), while the extended kin are aunts, uncles, cousins, nephews, and nieces. Given this background of family ties, the spouse in this study is also categorised in the family ties for her/his role is integral to an entrepreneur. The table above shows that Cases 1, 5, 6, 7, and 8 put their hope into the spouses, while the rest of the cases attached it to the parent (Case 3), children (Cases 2 and 4), and siblings (Cases 4 and 6). Nevertheless, for Cases 2 and 4, the roles of spouses emerged only when the business was at the developing stage, and in need of more support in marketing and finance. The result in relation to the spouse-entrepreneur relationship is consistent with De Maris' (2010) assertion that a love relationship is reflected in the business venture; that "a spouse exchanges the same type of 'commodities' with the other partner" (De Maris, 2010, p. 451).

To illustrate the evidence of SIHEA that are found between the entrepreneurs and their kin/blood relationships, they put forward:

My sons... all understand me, you know they could read my emotions, when I don't like certain things in the way... they organised the business, they simply know that [their] actions are not favoured by me to be carried out in running the business... err... meaning to say, we are emotionally attached to each other (Case 4).

SIHEA was found to integrate with trust and reciprocal commitment especially when the family members hold important responsibilities in the business venture, for example, Cases 1, 2, 4, and 6. The findings from these three cases show that the family ties possess high accountability in production process (Case 1) and being the main distributor agent of the products, while the siblings for Cases 4 and 6 were the main agents of distribution for the firm. When asked, the majority of the cases 
replied that love and affection relationships must come together with either trust or commitment when it comes to business relationships. Besides having trusted family members, performing important duties in operations of business does not require close monitoring and control, so the entrepreneurs could perform other important tasks.

\section{Trustworthiness}

Trust has been found in all cases when they create mandatory relationship with suppliers and customers for economic transactions, i.e., buying and selling matters, professional network for consultancy, government agencies for facilities and grants. This is consistent with Smith and Lohrke (2008) who mentioned that without a certain level of trust, it is impossible for entrepreneurs to perform successful economic transactions. In addition, the findings of the study showed that when trust is breached by the weak ties, particularly the customers (happened to Cases 2, 3, 4, 5, 6, and 8) they have no hesitation in rejecting them from their network relationships. A possible explanation for this is that weak ties which are not involving interpersonal interactions, as usually occurs in strong ties, might easily being dropped particularly when certain issues arise between them and the entrepreneurs. Furthermore, in line with Smith and Lohrke (2008), Case 3 put his strong trust in the other entrepreneurs in the joint venture of contract manufacturing, which has no contract agreement at all.

For the latter, findings show that the increase of trust is associated with the increasing intensity of the relationship, especially from weak to strong, that supports findings from the extant literature. In reference to Table 1, it shows, firstly, that trust governs the strong ties relationships with customers and suppliers (Cases 1, 7, and 8), and secondly, trust is the basis for strong relationships with siblings (Cases 2, 4, and 6 that are integrated with SIHEA).

Their relationship was based on SIHEA, trust, and commitment. There are several possible explanations for this. Firstly, SIHEA is the main theme, for they are the family members who are governed by strong emotional connection and blood relationship. Secondly, trust has been developed due to the kinship relation and the lack of confidence to put trust in the outsiders in performing key activities in the production department. Finally, the reciprocal commitment among each other resulted from the uncles and aunt who rely on Case 1 to earn for living, and at the same time reciprocated by Case 1 for he relied on their physical contribution in the production department and distribution of the products. 


\section{Reciprocal Commitment}

The findings show that reciprocal commitment governs the strong relationship of most of the cases (Cases 1, 2, 3, 4, 6, and 7) with the family members, other entrepreneurs, the distribution agent, and the suppliers. This finding supports the proposition made by Granovetter (1983). This study defines reciprocal commitments as mutual obligation between the entrepreneurs and the network ties, into which they are willing to invest resources. This finding notes interesting results; that is, the intensity of network ties increases when reciprocal commitment with the other themes increases, specifically with trustworthy and SIHEA.

The strong relationship with family members, i.e., the siblings, is not only based on high degrees of emotional attachment, but also reciprocal commitment that makes a strong relationship become even stronger. For example, Case 6's brother and sister were involved in the initial stage of business establishment, providing motivation and a small amount of financial help. After they retired, though, they also wanted to become entrepreneurs, and then started the production of cookies on a very small scale and sent them to their sister to sell at the market. They produced exactly the same products that followed the guidelines and recipe as well receiving the facilities from the sister and/or entrepreneur. She then buys the products from them and markets them. The strong business relationship between her and her siblings is governed by the reciprocal commitment among them. As the brother put forward:

My sister helps us in setting up our own business, and we produce the products exactly as what she wants, and we are so happy with this exchange for which I gain benefits from the business and I believe she has also increased her productivity (sibling of Case 6).

\section{Ties' Human Capital}

A new emerging finding in relation to the strength of relationships of the entrepreneur with the other network ties, regardless of whether they are family and/or personal ties or business ties is the tie's human capital. The extant literature shows that entrepreneurs' human capital is a necessary component for small business success and firm performance (Coleman, 1988); however, it overlooks on network ties' human capital as bases for entrepreneur to decide the strength of those ties. This study adds value to both network and human capital literature.

Findings reveal that four dimensions govern the discussion of human capital as the bases for network tie strengths, namely ties' knowledge, skills and/or 
competencies, experiences and networking, and/or social capital. Findings show that the human capital theme has strengthened the tie strengths of family members with the entrepreneurs which is dominated by SIHEA theme (Cases 1, 2, 4, 5, 6,7 , and 8 , with the exception of Case 3 which is a stand-alone case). This also contributed to the explanation of themes integration in discussing the bases of network tie strengths. To illustrate, knowledge that the children obtained from their academic qualification has caused the father to rely on them about machinery and technicalities of machine operations (son) and financial and marketing (daughter). The significance of their knowledge on the growth of business is noted here:

My daughter... graduated from a Business Studies degree while my son [is] in robotic engineering. I was lucky having them in this field although I was not planning this initially when they finished high school. Their knowledge gives advantages to my business (Case 2).

In relation to skills and/or competencies, Cases 5, 6, and 8 are blessed with having husbands who took on the responsibilities of marketing because of the skills and competencies they have in their previous involvement in business. The spouse is well-versed in the financial accounts of the firm (wife of Case 1), who also holds an accounting degree, and is the one who controlled the cash flows of the business in the starting-up phase. This is also evident with Cases 1, 3, 5, and 8.

\section{Ties' Attitudes and Values}

For network ties to evolve in strength, the entrepreneurs would screen the attitudes of the network ties: as the respondents stated, they would normally undergo the process of screening the network ties' attitudes, as the respondents put forward that:

...when I assess my distributor agent, I would look at his potential to grow his distribution company, his track record history, his positive attitude, and his kindliness (sensitivity)... for this will be the criteria to regard them to become my strong tie... (Case 5).

Cases 2, 3, 4, and 5 stated that the criteria they would use to assess their network ties' positive attitude are sincerity, high sense of responsibility, independence, truth, and concern for other's difficulties. As Case 2 said about the sincerity of his employee who has been working with him for 18 years, and has been deemed as his family, "His sincerity could be seen from his quality of work and services." Case 5 mentions that when the network ties, particularly the customers and suppliers, are upholding their responsibilities and performing their duties well, the relationships 
with them improve and evolve from weak to strong, and strong ties could become even stronger in every transaction. This positive attitude is attached to the level of trust, in the sense that the more good values they could offer, the more trust will increase in their relationships. She said:

My strong relationship between me and my distribution agent is based on the sense of responsibility... and it is very simple actually, whenever each of us performs our responsibility with... devotion, the level of trust will increase (Case 5).

\section{CONCLUSION, IMPLICATIONS, AND RECOMMENDATIONS}

The objective of the study is to determine the governance of network tie strength in entrepreneurial networking. This study found that the strength of ties was not only based on the SIHEA and trust, but also governed by the ties' human capital (knowledge, skills, experiences, and networking); their attitudes and values that dominate the contents of network relationships. It is also found that these themes are integrated among each other in entrepreneurial networking. This study adds value to both network and human capital literature that network ties' human capital plays crucial role in governing tie intensity in entrepreneurial network. Existing literature shows that entrepreneurs' human capital is necessary for small-business success; however, it tends to overlook network ties' human capital as basis for an entrepreneur to decide the strength of those ties.

This research study provides certain implications. Findings show that weak ties are mostly presented in the formal social network of entrepreneurship and strong in the informal network system. Therefore, SME entrepreneurs must take advantage of the social network for the development of their business activities. A systematic and informative social gathering provide opportunity, knowledge, and information. Entrepreneurs should also focus on the weak network accordingly. Weak ties give necessary information about the existing business markets situation and future opportunities. Having knowledge about the network tie governance revealed in this study, entrepreneurs must explore, develop, and strengthen the specific network ties of the social networks.

The entrepreneurial network studies suggested that business activities need strong networking facilities to enhance the economic activity (Anwar \& Shah, 2018). It is therefore necessary for the policy makers, government official, and other relevant stakeholders who would like to develop the SME entrepreneurs in their countries to make a networking strategy besides the old supporting approach. The finding of 
this research shows the importance of capital source formation which is the close family members, relatives, and friends, that is the social network. The government and other agencies support are also necessary to facilitate the SMEs. Hence, this study recommended to combine the formal and informal sources of financing for the development of SMEs business. Entrepreneurs must search effective ways and means to develop and strengthen the social networks.

Finally, several recommendations are proposed. First, we focused on the number of respondents working in the targeted industry. Perhaps different industries could add more value to the research so that the finding will be more rigour. Second, the research model has not explored demographic indicators and different regions in terms of cultural contexts and lifestyles. Hence, future studies should consider these characteristics for further develop the contextual understanding. Moreover, this case study is conducted in a specific geographic located in southern region of Malaysia while considering limited number of respondents and cases. Future studies should be extended to other geographic location by adding more respondents and cases. Finally, we further suggest future research scholars to investigate the role of other network ties such as invisibles ties in the case studies.

\section{REFERENCES}

Agbim, K.C. (2019). Social networking and the family business performance: A conceptual consideration. Journal of Entrepreneurship, Management and Innovation, 15(1), 83-122. https://doi.org/10.7341/20191514

Akrout, H., \& Diallo, M.F. (2017). Fundamental transformations of trust and its drivers: A multi-stage approach of business-to-business relationships. Industrial Marketing Management, 66, 159-171. https://doi.org/10.1016/j.indmarman.2017.08.003

Aldrich, H.E. \& Zimmer, C. (1986). Entrepreneurship through social networks. University of Illinois at Urbana-Champaign's Academy for Entrepreneurial Leadership Historical Research Reference in Entrepreneurship.

Anwar, M., \& Shah, S.Z.A. (2018). Managerial networking and business model innovation: Empirical study of new ventures in an emerging economy. Journal of Small Business \& Entrepreneurship, 32(3), 265-286. https://doi.org/10.1080/0827633 1.2018 .1490509

Bansal, S., Garg, I., \& Sharma, G.D. (2019). Social entrepreneurship as a path for social change and driver of sustainable development: A systematic review and research agenda. Sustainability, 11(4), 1091. https://doi.org/10.3390/su11041091

Birley, S., Cromie, S. \& Myers, A. (1991). Entrepreneurial networks: Their emergence in Ireland and overseas. International Small Business Journal, 9(4), 56-74. https:// doi.org/10.1177/026624269100900404

Brashears, M.E., \& Quintane, E. (2018). The weakness of tie strength. Social Networks, 55, 104-115. https://doi.org/10.1016/j.socnet.2018.05.010 
Brieger, S.A., \& De Clercq, D. (2019). Entrepreneurs' individual-level resources and social value creation goals: The moderating role of cultural context. International Journal of Entrepreneurial Behavior \& Research, 25(2), 193-216. https://doi. org/10.1108/IJEBR-12-2017-0503

Brown, J.S., \& Duguid, P. (2017). The social life of information. Harvard Business Review Press.

Bruderl, J., Preisendorfer, P., \& Ziegler, R. (1992). Survival chances of newly founded business organizations. American Sociological Review, 57, 227-242. https://doi. org/10.2307/2096207

Brush, C.G., Greene, P.G., \& Hart, M.M. (2001). From initial idea to unique advantage: The entrepreneurial challenge of constructing a resource base. Academy of Management Perspectives, 15(1), 64-78. https://doi.org/10.5465/ame.2001.4251394

Burt, R. (1992). The social structure of competition. Harvard University Press.

Coleman, J. S. (1988). Social capital in the creation of human capital. The American Journal of Sociology, 94, S95-S120. https://doi.org/10.1086/228943

Dahl, M.S., \& Sorenson, O. (2009). The embedded entrepreneur. European Management Review, 6, 172-181. https://doi.org/10.1057/emr.2009.14

De Maris, A. (2010). The 20-year trajectory of marital quality in enduring marriages: Does equity matter? Journal of Social and Personal Relationships, 27, 449-471.

Dubini, P., \& Aldrich, H. (1991). Personal and extended networks are central to the entrepreneurial process. Journal of Business Venturing, 6, 305-313. https://doi. org/10.1016/0883-9026(91)90021-5

Durda, L., \& Ključnikov, A. (2019). Social networks in entrepreneurial startups development. Economics \& Sociology, 12(3), 192-208. https://doi.org/10.14254/2071 $-789 X .2019 / 12-3 / 13$

Elfring, T., \& Hulsink, W. (2007). Networking by entrepreneurs: Patterns of tie-formation in emerging organizations. Organization Studies, 28, 1849-1872. https://doi. org/10.1177/0170840607078719

Granovetter, M. (1973). The strength of weak ties. The American Journal of Sociology, 78, 1360-1380. https://doi.org/10.1086/225469

Granovetter, M. (1983). The strength of weak ties: A network theory revisited. Sociological Theory, 1, 201-233. https://doi.org/10.2307/202051

Greco, A., \& De Jong, G. (2017). Sustainable entrepreneurship: Definitions, themes and research gaps. (Working paper series vol. 6, no. 17). Leeuwarden, The Netherlands: Rijksuniversiteit Groningen/Campus Fryslân.

Hirsch, B., Nitzl, C., \& Schoen, M. (2018). Interorganizational trust and agency costs in credit relationships between savings banks and SMEs. Journal of Banking \& Finance, 97, 37-50. https://doi.org/10.1016/j.jbankfin.2018.09.017

Hoang, H., \& Antoncic, B. (2003). Network-based research in entrepreneurship - A critical review. Journal of Business Venturing, 18, 165-187.

Huang, L., \& Knight, A.P. (2017). Resources and relationships in entrepreneurship: An exchange theory of the development and effects of the entrepreneur-investor relationship. Academy of Management Review, 42(1), 80-102. https://doi. org/10.5465/amr.2014.0397 
Jack, S., Dodd, S., \& Anderson, A. (2004). Social structures and entrepreneurial networks: the strength of strong ties. The International Journal of Entrepreneurship and Innovation, 5, 107-120. https://doi.org/10.5367/000000004773863264

Jack, S.L. (2005). The role, use and activation of strong and weak network ties: A qualitative analysis. Journal of Management Studies, 42, 1233-1259. https://doi. org/10.1111/j.1467-6486.2005.00540.x

Jiang, X., Liu, H., Fey, C., \& Jiang, F. (2018). Entrepreneurial orientation, network resource acquisition, and firm performance: A network approach. Journal of Business Research, 87, 46-57. https://doi.org/10.1016/j.jbusres.2018.02.021

Jones, O., \& Conway, S. (2004). The international reach of entrepreneurial social networks: The case of James Dyson in the UK. In H. Etemad (Ed.), International entrepreneurship in small and medium-sized enterprises: Orientation, environment and strategy (vol. 3, pp. 87-106). Edward Elgar Publishing.

Klyver, K., Honig, B., \& Steffens, P. (2018). Social support timing and persistence in nascent entrepreneurship: exploring when instrumental and emotional support is most effective. Small Business Economics, 51(3), 709-734. https://doi. org/10.1007/s11187-017-9964-5

Larson, A. (1992). Network dyads in entrepreneurial settings: A study of the governance of exchange relationships. Administrative Science Quarterly, 37, 76-104. https:// doi.org/10.2307/2393534

Lechner, C. \& Dowling, M. (2003). Firm networks: External relationships as sources for the growth and competitiveness of entrepreneurial firms. Entrepreneurship \& Regional Development, 15, 1-26. https://doi.org/10.1080/08985620210159220

Lorenzo, G. \& Lipparini, A. (1999). The leverage of interfirm relationships as a distinct organizational capability. Strategic Management Journal, 20, 317-338.

Lux, S., Lamont, B.T., Ellis, K.M., Ferris, G.R., \& Muchira, J. (2016). Developing and utilizing efficient ties in entrepreneurial networks in Africa. Africa Journal of Management, 2(1), 73-92.

Meyskens, M., Carsrud, A.L., \& Cardozo, R.N. (2010). The symbiosis of entities in the social engagement network: The role of social ventures. Entrepreneurship and Regional Development, 22(5), 425-455.

Omar, S.S., Arokiasamy, L. \& Ismail, M. (2009). The background and challenges faced by the small medium enterprises: A human resource development perspective. International Journal of Business and Management, 4, 95-102. https://doi. org/10.5539/ijbm.v4n10p95

Opondo, M.A. (2017). The role of business incubators towards promoting small business growth in gauteng province [Doctoral dissertation, University of Johannesburg].

Ozdemir, S.Z., Moran, P., Zhong, X., \& Bliemel, M.J. (2016). Reaching and acquiring valuable resources: The entrepreneur's use of brokerage, cohesion, and embeddedness. Entrepreneurship Theory and Practice, 40(1), 49-79. https://doi. org/10.1111/etap.12103

Paerregaard, K. (2018). Capitalizing on migration: The role of strong and weak ties among Peruvian entrepreneurs in the United States, Spain and Chile. Migration Studies, 6(1), 79-98. https://doi.org/10.1093/migration/mnx032 
Ren, S., Shu, R., Bao, Y., \& Chen, X. (2016). Linking network ties to entrepreneurial opportunity discovery and exploitation: the role of affective and cognitive trust. International Entrepreneurship and Management Journal, 12(2), 465-485. https://doi.org/10.1007/s11365-014-0350-3

Reynolds, P., Bygrave, W., Autio, E., Arenius, P., \& Monitor, G. (2004). GEM 2003 Global Report, Babson College.

Rost, K. (2011). The strength of strong ties in the creation of innovation. Research Policy, 40(4), 588-604. https://doi.org/10.1016/j.respol.2010.12.001

Rowley, T., Behrens, D. \& Krackhardt, D. (2000). Redundant governance structures: An analysis of structural and relational embeddedness in the steel and semiconductor industries. Strategic Management Journal, 21, 369-386.

Schell, S., Hiepler, M., \& Moog, P. (2018). It's all about who you know: The role of social networks in intra-family succession in small and medium-sized firms. Journal of Family Business Strategy, 9(4), 311-325. https://doi.org/10.1016/ j.jfbs.2018.08.003

Shu, R., Ren, S., \& Zheng, Y. (2018). Building networks into discovery: The link between entrepreneur network capability and entrepreneurial opportunity discovery. Journal of Business Research, 85, 197-208. https://doi.org/10.1016/ j.jbusres.2017.12.048

Smith, D.A., \& Lohrke, F.T. (2008). Entrepreneurial network development: Trusting in the process. Journal of Business Research, 61, 315-22. https://doi.org/10.1016/ j.jbusres.2007.06.018

Soderqvist, A. \& Chetty, S. (2009). Strength of ties and their role in pre-founding, startup and early internationalization. 12th McGill International Entrepreneurship Conference, Vaasa, Finland.

Soetanto, D. (2017). Networks and entrepreneurial learning: Coping with difficulties. International Journal of Entrepreneurial Behavior \& Research, 23(3).

Teixeira, R.M., Andreassi, T., Köseoglu, M.A., \& Okumus, F. (2019). How do hospitality entrepreneurs use their social networks to access resources? Evidence from the lifecycle of small hospitality enterprises. International Journal of Hospitality Management, 79, 158-167. https://doi.org/10.1016/j.ijhm.2019.01.006

Tran, A.T., \& Von Korflesch, H. (2016). A conceptual model of social entrepreneurial intention based on the social cognitive career theory. Asia Pacific Journal of Innovation and Entrepreneurship, 10(1). 